\title{
Menstrual Cycle Characteristics of Healthcare Professionals Working at COVID-19 Pandemic Clinics
}

\author{
Devcan Arzu ARINKANa, ${ }^{\text {D }}$ Fisun VURAL ${ }^{a}$ \\ ${ }^{a}$ Department of Obstetrics and Gynecology, University of Health Sciences Haydarpaşa Numune Training and Research Hospital, \\ İstanbul, TURKEY
}

\begin{abstract}
Objective: The impact of severe acute respiratory syndrome-coronavirus-2 (SARS-CoV-2) infection on the reproductive system is still not known. We aimed to investigate the menstrual characteristics of healthcare professionals employed in the coronavirus disease2019 (COVID-19) clinics and to investigate whether COVID-19 alters the pattern of the menstrual cycle. Material and Methods: This cross-sectional study was conducted on 275 healthcare professionals. Results: During the pandemic, $12 \%$ of the cases experienced irregular cycles, and $33.8 \%$ of the cases reported that their amount of bleeding had changed. Also, $23.6 \%$ of the cases had an increase in dysmenorrhea. The ratio of dysmenorrhea, irregular cycle, changes in bleeding time, and amount of bleeding were similar in doctors, nurses, and other healthcare professionals $(\mathrm{p}>0.05)$. Among all cases, $20.4 \%(\mathrm{n}=56)$ had SARS-CoV-2 infection. The ratio of increase at dysmenorrhea was found to be significantly higher in women who had SARS-CoV-2 infection $(35.7 \%$ vs $20.5 \%)(p=0.022 ; \mathrm{p}<0.05)$. Besides, the ratio of cases that experienced changes in their amount of bleeding was found to be higher in SARS-CoV-2 group $(53.6 \%$ vs $28.8 \%)(p=0.001 ; p<0.05)$. There was no statistically significant difference between cases who had infection and those who did not have regarding having an irregular cycle and change in duration of bleeding ( $p>0.05$ ). Conclusion: The menstrual pattern and cycle length did not change significantly during the pandemic. Also, SARS-CoV-2 infected cases reported a difference in the amount of bleeding and increased dysmenorrhea after infection. This study provides first step to establish whether COVID-19 has an immediate impact on menstrual function.
\end{abstract}

Keywords: COVID-19 infection; menstrual cycle; dysmenorrhea; irregular cycle

Coronavirus disease-2019 (COVID-19) pandemics infected millions of people around the world, causing thousands of deaths. In this global struggle, healthcare professionals work at the forefront. The COVID-19 pandemic period has impacted healthcare workers physically and psychologically. Healthcare workers work under stressful conditions and involve difficult decisions as ethical implications. Increased work demands on healthcare professionals conflict with their duties to family and friends, which causes psychological stress. All of these factors may negatively affect the menstrual cycle. Studies have been conducted concerning working conditions, long working hours, shifts, and menstrual irregularities among healthcare professionals. However, there is no study on the menstrual characteristics of healthcare professionals during the pandemic period.

Severe acute respiratory syndrome-coronavirus2 (SARS-CoV-2) enters the host cell by using similar receptors as angiotensin-converting enzyme 2 (ACE2), and transmembrane protease serine system. ${ }^{1}$ Organs with high expression of these molecules were considered as targets of infection. Expression of ACE2 in endometrium tissue was reported and it was demonstrated that this expression might be changed during the menstrual cycle. ${ }^{1}$ The impact of SARSCoV-2 infection on the reproductive system is still not known. In this article, we aimed to investigate the menstrual characteristics of healthcare professionals employed in the COVID-19 pandemic clinic and to investigate further whether COVID-19 alters the pattern of the menstrual cycle.

Correspondence: Sevcan Arzu ARINKAN

Department of Obstetrics and Gynecology, University of Health Sciences Haydarpaşa Numune Training and Research Hospital, İstanbul, TURKEY

E-mail: pataraa96@gmail.com

Peer review under responsibility of Journal of Clinical Obstetrics \& Gynecology. 


\section{MATERIAL AND METHODS}

This cross-sectional study was conducted on healthy female participants who were working at COVID-19 pandemic clinics at Haydarpaşa Numune Research and Training Hospital in Turkey between April 2020 and September 2020. Every healthcare professional working at the COVID-19 clinics received COVID19 antibody scan during the pandemic. Polymerase chain reaction test was performed on those who were positive for immunoglobulin $\mathrm{G}(\mathrm{IgG})$ and $\operatorname{IgM}$. All cases were questioned about their menstrual cycles at least one month after they had started working in the pandemic clinic. SARS-CoV-2 infected healthcare workers were interviewed for their first menstrual cycle after the infection. Healthcare professionals were required to undertake a health examination annually. Annual health checks were evaluated, hospital records were scanned. The exclusion criteria were pregnancy, history of gynecological surgery, oral contraceptive use, prior menstrual irregularity, endometriosis, intrauterine device users, malignancy, primary amenorrhea, menopause, and lactation.

After informed consent, detailed information was collected using structured questionnaires by faceto-face interviews, and cases were asked to check their menstrual cycle calendars. The questionnaire included questions about menstrual cycle characteristics (cycle length, duration, and amount of bleeding) and dysmenorrhea. Besides, we asked three openended questions: 'Have you experienced increase in your pain during menses in the pandemic period?' 'Have you experienced an irregular menstrual cycle during the pandemic period?' 'Have you experienced a change in either amount or duration of bleeding during the pandemic period?' Irregular menstrual cycles were defined as more than six days absolute difference between any two consecutive menstrual cycles. ${ }^{2}$ The cycle length was defined as the time from the first day of bleeding to the new onset of bleeding. ${ }^{2}$ More than six peds in a day was accepted as heavy bleeding. Dysmenorrhea was defined as lower abdominal pain during menses at any time during the past six months. ${ }^{3}$

The study was approved by the Haydarpaşa Numune Training and Research Hospital Ethics and Clinical Investigation Committee (HNEAH/ 2020/
KK/83, April 2020) and Ministry of Health. Additionally this study confirmed the principles embodied in the Declaration of Helsinki. The sample size was calculated via a simple random sampling method in the study universe. Informed consent was taken from all patients. Statistical analyses were done by using Statistical Package for the Social Sciences (SPSS; Version 22.0, IBM Turkey). Descriptive statistics (mean, standard deviation, frequency) were used. The normality distribution of the data was evaluated with Kolmogorov-Smirnov test. Chi-square test and Fischer Exact test were used for comparison of qualitative data. Mann-Whitney $U$ was used for the data not normally distributed. Results were evaluated with a confidence interval of $95 \%$, and $p<0.05$ was considered statistically significant.

\section{RESULTS}

A total of 310 healthcare workers agreed to participate, 275 healthcare professionals were included in the study. The mean age of the cases was $30.32 \pm 6.26$ years, work experience was $4.23 \pm 3.98$ years (Table 1). The demographic characteristics of the cases are shown in Table 1.

During the pandemic, $12.1 \%(\mathrm{n}=33)$ of the cases experienced irregular cycles, and $33.8 \%(n=93)$ of the cases reported that their amount of bleeding had changed. Also, 23.6\% $(n=65)$ of the cases had an increase in dysmenorrhea. Table 2 shows the details of menstrual characteristics of all cases during the pandemic period. The ratio of dysmenorrhea, irregular cycle, changes in bleeding time, and amount of bleeding were similar in different medical professional groups (doctor, nurses, and other healthcare professionals) ( $\mathrm{p}>0.05)$.

Overall, $20.4 \%(n=56)$ had SARS-CoV-2 infection. Of these patients, $66 \%(\mathrm{n}=37)$ received hydroxychloroquine treatment, $28.5 \%(\mathrm{n}=16)$ received favipiravir treatment, and $5.5 \%(\mathrm{n}=3)$ did not receive any treatment. There was no statistically significant difference between the cases who had infection and those who did not, concerning demographic characteristics $(\mathrm{p}>0.05)$. Healthcare professionals that had the infection and those who did not have had similar work experience $(4.61 \pm 3.87$; vs $4.14 \pm 4.02$ years, $\mathrm{p}>0.05)$. The ratio of increase in dysmenorrhea was 


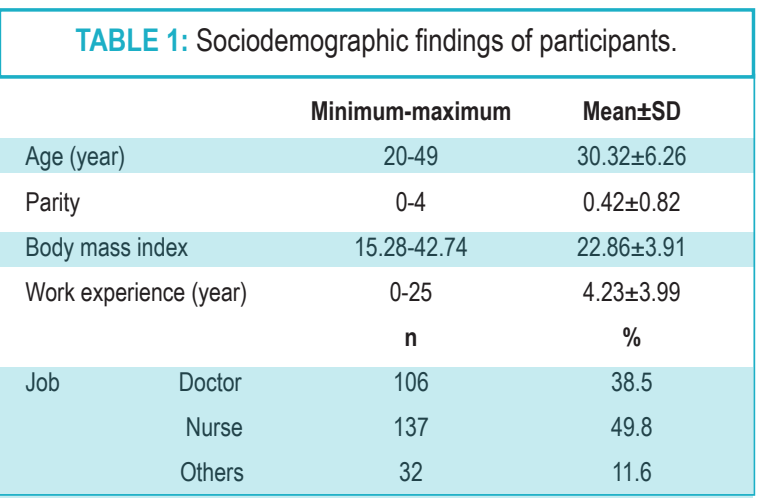

SD: Standard deviation

found to be significantly higher in SARS-CoV-2 group $(35.7 \%$ vs $20.5 \%)(p=0.022 ; p<0.05)$. There was no statistically significant difference between groups regarding having an irregular cycle and change in the duration of bleeding ( $p>0.05)$. However, the ratio of cases having a change in their amount of bleeding was found to be higher in SARSCoV-2 group (53.6\% vs $28.8 \%)(\mathrm{p}=0.001 ; \mathrm{p}<0.05)$ (Table 3). While $50 \%(\mathrm{n}=8)$ of women who had favipiravir therapy reported change in duration of bleeding, $16 \%(n=6)$ of women having hydroxychloroquine reported change in duration of bleeding. This difference was statistically significant $(\mathrm{p}=0.017$; $\mathrm{p}<0.05$ ). However, there was no significant difference between hydroxychloroquine and favipiravir groups regarding increase in dysmenorrhea $(p=0.758$; $\mathrm{p}<0.05)$.

\section{DISCUSSION}

During COVID-19 pandemic, healthcare professionals work at the forefront and become under a physical and psychological burden. Regular menstruation is a sign of a healthy reproductive system. This study investigated the menstrual characteristics of healthcare professionals during the pandemic. As far as we know, this article is the first article to investigate the effects of the pandemic period and SARS-CoV-2 infection on menstrual patterns. This study briefly found that the menstrual pattern did not change much during the pandemic period. However, of the SARS-CoV-2 infected cases, 53.6\% reported a change in the amount of their bleeding, $35.7 \%$ reported an increase in dysmenorrhea.

The working conditions and menstrual patterns of healthcare professionals have been investigated in many studies. The most common symptom in gynecology practice is menstrual irregularities. Disruption of the circadian rhythm, overtime work, and stressful conditions may impair the function of the uterus, ovaries, and the hypothalamic-pituitary system axis and lead to menstrual disorders. ${ }^{4,5}$ Menstrual dysfunction impairs the life quality of women and work performance, therefore, lead to a severe economic burden. Women with irregular menstrual cycles had a 53\% higher incidence of heart disease compared to women with regular cycles. ${ }^{6}$ In a cohort study, it was suggested that women with irregular menstrual cycles had an increased risk of ovarian cancer. ${ }^{7}$ There

\begin{tabular}{|lccc|}
\hline & TABLE 2: & Menstrual characteristic of healthcare workers during the pandemic. \\
\hline & & Mean \pm SD & Minimum-maximum \\
\hline Length of cycle (day) & & $29.68 \pm 8.13$ & $15-90$ \\
\hline Duration of bleeding (day) & & $6.04 \pm 2.45$ & $1-30$ \\
Amount of bleeding (ped/daily) & & $4.17 \pm 1.86$ & $1-13$ \\
\hline Irregular menstrual cycle & Yes & $\mathrm{n}$ & 12 \\
& No & 33 & 88 \\
\hline Change in duration of bleeding & Yes & 242 & 26.9 \\
& No & 74 & 73.1 \\
Change in amount of bleeding & Yes & 201 & 33.8 \\
& No & 93 & 66.2 \\
\hline Increase in dysmenorrhea & Yes & 182 & 23.6 \\
& No & 65 & 76.4 \\
\hline
\end{tabular}

SD: Standard deviation. 


\begin{tabular}{|c|c|c|c|c|}
\hline & & COVID-19 group $(n=56)$ & Control group $(n=219)$ & \\
\hline & & Mean $\pm S D$ & Mean $\pm S D$ & $p$ value \\
\hline Body mass index & & $23.39 \pm 3.49$ & $22.74 \pm 4$ & ${ }^{1} 0.204$ \\
\hline Age (year) & & $30.30 \pm 6.57$ & $30.33 \pm 6.2$ & ${ }^{1} 0.753$ \\
\hline Parity & & $0.42 \pm 0.85$ & $0.42 \pm 0.81$ & ${ }^{1} 0.777$ \\
\hline \multirow[t]{2}{*}{ Experience (years) } & & $4.61 \pm 3.87$ & $4.14 \pm 4.02$ & ${ }^{1} 0.287$ \\
\hline & & $\mathrm{n}(\%)$ & $\mathrm{n}(\%)$ & \\
\hline \multirow[t]{2}{*}{ Irregular cycle } & Yes & $8(14.3 \%)$ & $25(11.4 \%)$ & ${ }^{2} 0.555$ \\
\hline & No & $48(85.7 \%)$ & $194(88.6 \%)$ & \\
\hline \multirow[t]{2}{*}{ Change in duration of bleeding } & Yes & $16(28.6 \%)$ & $58(26.5 \%)$ & ${ }^{2} 0.753$ \\
\hline & No & $40(71.4 \%)$ & $161(73.5 \%)$ & \\
\hline \multirow[t]{2}{*}{ Change in amount of bleeding } & Yes & $30(53.6 \%)$ & $63(28.8 \%)$ & ${ }^{3} 0.001^{* *}$ \\
\hline & No & $26(46.4 \%)$ & $156(71.2 \%)$ & \\
\hline \multirow[t]{2}{*}{ Inrease in dysmenorrhea } & Yes & $20(35.7 \%)$ & $45(20.5 \%)$ & ${ }^{3} 0.022^{*}$ \\
\hline & No & $36(64.3 \%)$ & $174(79.5 \%)$ & \\
\hline
\end{tabular}

${ }^{1}$ Mann-Whitney U test; ${ }^{2}$ Chi-square test; ${ }^{3}$ Fischer's Exact test; ** $p<0.001,{ }^{*} p<0.05$; SD: Standard deviation.

are many studies in the literature demonstrating the association between shift work and adverse reproductive health outcomes such as irregular menstrual cycle, dysmenorrhea, subfertility, preterm birth, and low birth weight. ${ }^{8,9}$ Shorter menstrual cycles and irregular menstrual cycles were reported among nurses working at night shifts. ${ }^{10,11}$ Nurses' Health Study II included 71077 women and showed an association between the duration of the working at rotating shift and irregular cycles. ${ }^{12}$ Also, they reported that moderately short (21-25 days) or long (32-39 days) cycle lengths were not associated with shift working. No increased risk of having menstrual disorders was reported among nurses on the rotating shift in another observational study that included 113 workers on the rotating night shift and 75 on the day shift. ${ }^{13}$

It was found that the irregular menstruation rate was higher among the nurses. ${ }^{4}$ A national-based study in China reported that the ratio of female nurses who experienced menstrual disorders (41\%) was significantly higher than those of non-nurse health care workers. ${ }^{4}$ Another study in Norway showed that the prevalence of irregular menstruation was 1 out of 6 nurses. ${ }^{14}$ In our study, $12 \%$ of the healthcare professionals reported irregular menstrual cycles, and $33.8 \%$ of the cases reported that their amount of bleeding had changed during the pandemic. In a population-based cohort study, the nurses and doctors ex- hibited significantly increased risks in medical services utilization for menstrual disorders compared with medical technologists and therapists. ${ }^{15}$ In our study, we detected no significant difference between medical professional groups (doctor, nurses, and others) regarding having the irregular cycle, increase at dysmenorrhea, change in bleeding time, and change in the amount of bleeding $(\mathrm{p}>0.05)$.

Dysmenorrhea is a condition that impairs women's work capacities and affects the quality of life. In the literature, the prevalence of dysmenorrhea among nurses was reported as over $70 \% .{ }^{16,17}$ It was reported that dysmenorrhea was 4.06 times common among nurses younger than 40 years than older. They also reported an increased dysmenorrhoea rate among unmarried nurses. ${ }^{3}$ In our study, none of the participants in the study group had a known gynecological pathology or oral contraceptive use. Also, 23.6\% $(n=65)$ of the participants reported an increase in their dysmenorrhea during the pandemic. Besides, 35.7\% (20/56) of those infected with SARS-CoV-2 reported an increase in dysmenorrhea. At the beginning of menses, prostaglandins are released from the endometrium and induce uterine contractions. Prostaglandins (especially E2 and F2 alpha) are increased in primary dysmenorrhea. Elevated levels of Prostaglandin E2 have a role in inflammation. PGE2 is thought to be effective in COVID-19 pathophysiology. Also, 
measuring PGE2 levels in patients and selective inhibition of the human microsomal prostaglandin E synthase-1 as a potential therapeutic approach was suggested. ${ }^{18}$ We believe that increase in dysmenorrhea at SARS-CoV-2 infected cases may be due to increased inflammatory response or stress-related factors.

There are some potential limitations. This study was based on self-reported menstrual cycle changes during the COVID-19 pandemic. Confounding factors such as different therapy regimens (hydroxychloroquine and favipiravir) might affect menstrual cycle. Regression analysis with larger population might be performed in order to asses these risk factors. The number of the SARS-CoV-2 infected cases and small population at different therapy groups were other limitations. However, there is still no study about the association of the menstrual characteristics and SARS-CoV-2 infection in the literature.

\section{CONCLUSION}

The menstrual pattern did not change much during the pandemic period. However, of the SARS-CoV-2 infected cases, $53.6 \%$ reported a change in the amount of their bleeding, 35.7\% reported an increase in dysmenorrhea. This study provides the first step to establish whether COVID-19 has an immediate impact on menstrual function to investigate whether COVID-19 has long-term reproductive health implications.

IRB ethical approval: NCT04413058 on 08. 04.2020

\section{Source of Finance}

During this study, no financial or spiritual support was received neither from any pharmaceutical company that has a direct connection with the research subject, nor from a company that provides or produces medical instruments and materials which may negatively affect the evaluation process of this study.

\section{Conflict of Interest}

No conflicts of interest between the authors and / or family members of the scientific and medical committee members or members of the potential conflicts of interest, counseling, expertise, working conditions, share holding and similar situations in any firm.

\section{Authorship Contributions}

Idea/Concept: Sevcan Arzu Arinkan; Design: Sevcan Arzu Arinkan; Control/Supervision: Sevcan Arzu Arinkan; Data Collection and/or Processing: Sevcan Arzu Arinkan; Analysis and/or Interpretation: Sevcan Arzu Arinkan; Literature Review: Sevcan Arzu Arinkan, Fisun Vural; Writing the Article: Sevcan Arzu Arinkan; Critical Review: Sevcan Arzu Arinkan, Fisun Vural; References and Fundings: Sevcan Arzu Arinkan.

\section{REFERENCES}

1. Li R, Yin T, Fang F, Li Q, Chen J, Wang Y, et al. Potential risks of SARS-CoV-2 infection on reproductive health. Reprod Biomed Online. 2020;41(1):89-95. [Crossref] [Pubmed] [PMC]

2. Smith-DiJulio K, Mitchell ES, Woods NF. Concordance of retrospective and prospective reporting of menstrual irregularity by women in the menopausal transition. Climacteric. 2005; 8(4):390-7. [Crossref] [Pubmed] [PMC]

3. Chiu MH, Hsieh HF, Yang YH, Chen HM, Hsu SC, Wang $\mathrm{HH}$. Influencing factors of dysmenorrhoea among hospital nurses: a questionnaire survey in Taiwan. BMJ Open. 2017;7(12):e017615. [Crossref] [Pubmed] [PMC]

4. Jiang Z, Wang J, Guo X, Feng L, Yu M, Zhou J, et al. Menstrual disorders and occupational exposures among female nurses: A nationwide cross-sectional study. Int J Nurs Stud. 2019;95:49-55. [Crossref] [Pubmed]

5. Lawson CC, Johnson CY, Chavarro JE, Lividoti Hibert EN, Whelan EA, Rocheleau CM, et al. Work schedule and physically demanding work in relation to menstrual function: the Nurses' Health Study 3. Scand J Work Environ Health. 2015;41(2):194-203. [Crossref] [Pubmed]

6. Solomon CG, Hu FB, Dunaif A, Rich-Edwards JE, Stampfer MJ, Willett WC, et al. Menstrual cycle irregularity and risk for future cardiovascular disease. J Clin Endocrinol Metab. 2002;87(5):2013-7. [Crossref] [Pubmed]
7. Cirillo PM, Wang ET, Cedars MI, Chen LM, Cohn BA Irregular menses predicts ovarian cancer: Prospective evidence from the Child Health and Development Studies. Int J Cancer. 2016;139(5):1009-17. [Crossref] [Pubmed] [PMC]

8. Kang W, Jang KH, Lim HM, Ahn JS, Park WJ. The menstrual cycle associated with insomnia in newly employed nurses performing shift work: a 12-month follow-up study. Int Arch Occup Environ Health. 2019;92(2):227-35. [Crossref] [Pubmed]

9. Mahoney MM. Shift work, jet lag, and female reproduction. Int J Endocrinol. 2010;2010: 813764. [Crossref] [Pubmed] [PMC]

10. Chung FF, Yao CC, Wan GH. The associations between menstrual function and life style/working conditions among nurses in Taiwan. J Occup Health. 2005;47(2):149-56. [Crossref] [Pubmed]

11. Wan GH, Chung FF. Working conditions associated with ovarian cycle in a medical center nurses: a Taiwan study. Jpn J Nurs Sci. 2012;9(1):112-8. [Crossref] [Pubmed]

12. Lawson CC, Whelan EA, Lividoti Hibert EN, Spiegelman D, Schernhammer ES, Rich-Edwards JW. Rotating shift work and menstrual cycle characteristics. Epidemiology. 2011; 22(3):305-12. [Crossref] [Pubmed] [PMC]
13. Albert-Sabater JA, Martínez JM, Baste V, Moen BE, Ronda-Perez E. Comparison of menstrual disorders in hospital nursing staff according to shift work pattern. J Clin Nurs. 2016;25(21-22):3291-9. [Crossref] [Pubmed]

14. Moen BE, Baste V, Morken T, Alsaker K, Pallesen S, Bjorvatn $B$. Menstrual characteristics and night work among nurses. Ind Health. 2015;53(4):354-60. [Crossref] [Pubmed] [PMC]

15. Koo M, Chen CH, Tsai KW, Lu MC, Lin SC. Ambulatory medical services utilization for menstrual disorders among female personnel of different medical professions in Taiwan: a nationwide retrospective cohort study. BMC Womens Health. 2015;15:66. [Crossref] [Pubmed] [PMC]

16. Chiu MH, Wang HH, Hsu SC, Liu IP. Dysmenorrhoea and self-care behaviours among hospital nurses: a questionnaire survey. J Clin Nurs. 2013;22(2122):3130-40. [Crossref] [Pubmed]

17. Chuamoor K, Kaewmanee K, Tanmahasamut P. Dysmenorrhea among Siriraj nurses; prevalence, quality of life, and knowledge of management. J Med Assoc Thai. 2012;95(8): 983-91. [Pubmed]

18. Smeitink J, Jiang X, Pecheritsyna S, Renkema H, van Maanen R, Beyrath J. Hypothesis: mPGES-1-Derived Prostaglandin E2, a So Far Missing Link in COVID-19 Pathophysiology? 2020. [Crossref] 